EXTENDED REPORT

\title{
Glutathione $\mathrm{S}$ transferase $\mathrm{M} 1$ and $\mathrm{T} 1$ genetic polymorphisms are related to the risk of primary open-angle glaucoma: a study in a Turkish population
}

\author{
Mustafa Ünal, Mehmet Güven, Kazım Devranoğlu, Ahmet Özaydın, Bahadır Batar, Nevbahar \\ Tamçelik, Ebru Eroğlu Görgün, Didar Uçar, Ahmet Sarıcı
}

Br J Ophthalmol 2007;91:527-530. doi: 10.1136/bjo.2006.102418

See end of article for authors' affiliations

Correspondence to

M Ünal, Demircikara mah,

1426 sk Zeybek apt, B blok

Nol4/12, Muratpașa/

Antalya, Turkey;

mustafaunalmd@gmail.com

Accepted 1 September 2006

Published Online First

14 September 2006
Background: Genetic factors and oxidative damage have been shown to have a role in the development of primary open angle glaucoma (POAG).

Aim: To determine the effects of genetic polymorphisms of glutathione S transferase (GST)M1 and GSTT1 on the risk of POAG in a Turkish population.

Methods: Using a multiplex polymerase chain reaction (PCR), GSTM1 and GSTT1 gene polymorphisms were analysed in 144 patients with POAG and in 121 otherwise healthy controls of similar age.

Results: The GSTM1 positive genotype and the GSTT1 null genotype had an increased risk of developing POAG ( $p<0.001$, OR 2.93, 95\% Cl 1.66 to 5.20 and OR 4.25, 95\% Cl 2.30 to 7.80 , respectively). The risk of glaucoma also increased significantly in subjects with a combination of GSTM1 positive and GSTT1 null genotypes ( $p<0.001$, OR 3.46, 95\% Cl 1.64 to 7.38).

Conclusion: The GSTM1 positive genotype and GSTT1 null genotype or the combination of both may be associated with the increased risk of development of POAG in the Turkish population.
$\mathrm{P}$

rimary open angle glaucoma (POAG) is the most common form of glaucoma. POAG is a complex chronicdegenerative disease having a multifactorial aetiology including mechanical damage due to increased intraocular pressure (IOP), increased glutamate levels, mutations in specific genes, toxic effects and oxidative damage caused by reactive oxygen species (ROS). The pathogenic role of ROS in glaucoma is supported by various experimental findings. ROSmediated oxidative DNA damage has also been shown to be significantly increased in the trabecular meshwork of patients with glaucoma compared with controls. Oxidative stress also seems to be involved in the neuronal cell death affecting the optic nerve in POAG. ${ }^{1-4}$

Glutathione S transferases (GSTs) represent an important family of phase II drug metabolising enzymes. Besides detoxifying exogenous electrophilic xenobiotics, these transferases inactivate endogenous end products formed as secondary metabolites during oxidative stress..$^{5-8}$

The GST isoenzymes expressed in human tissues comprise the alpha, mu, pi, theta, kappa, sigma, zeta and omega gene families. ${ }^{9}$ As many GST genes are polymorphic, there has been considerable interest in determining whether particular allelic variants are associated with altered risk (or outcome) of a variety of pathologies including cancers, cardiovascular diseases and respiratory diseases. ${ }^{56}$

Of these classes of GSTs, five (GSTM1, GSTM3, GSTT1, GSTPI and GSTZ1) have been shown to be polymorphically distributed. ${ }^{10}$ Five mu-class genes (GSTMI-GSTM5) are situated on chromosome 1. ${ }^{11}$ Polymorphisms identified in GSTMI are $\mathrm{GSTMI}^{*} 0, \mathrm{GSTMI}^{*} \mathrm{~A}$ and GSTMI${ }^{*} \mathrm{~B}$. GSTMI${ }^{*} 0$ is deleted, and homozygotes (GSTMl null genotype) express no protein. GSTMI*A and GSTMI*B differ by a single base, and the catalytic effectiveness of the enzymes encoded by these alleles is similar. There are two theta-class genes, GSTT1 and GSTT2, located on chromosome $22 .{ }^{6}$ GSTTl is represented by two alleles: a functional or wild allele $\left(\mathrm{GSTTl}^{*} 1\right)$, and a nonfunctional or null allele $\left(G_{S T T l}{ }^{*} 0\right)$. Studies have shown that the GSTTI ${ }^{*} 0$ allele corresponds to a total or partial deletion of the gene, causing a deficiency in enzymatic activity. ${ }^{12}$

In the current study, we investigated the distribution of the GSTMI and GSTT1 polymorphisms in patients with POAG and controls to explore the possible association between different GST variants and the incidence of POAG.

\section{MATERIALS AND METHODS}

\section{Patients and controls}

This case-control study comprised 144 patients with POAG and 121 disease-free controls. All were from Turkey. All subjects selected were non-smokers and did not have diabetes mellitus or other systemic diseases. Informed consent was obtained from all subjects after explanation of the nature of the study.

Each subject underwent a complete ophthalmological examination. Patients with POAG were defined by the presence of an open angle, pathological cupping of the optic disc, a glaucoma hemifield test (GHT) outside normal limits with reproducible visual field defects at the same location on two consecutive visits, and an IOP $>21 \mathrm{~mm} \mathrm{Hg}$ without anti-glaucoma drugs. The mean IOP level was 23.9 (1.2) mm Hg (range 22-29 mm $\mathrm{Hg}$ ) at the time of diagnosis. Cup-to-disc ratios were between 0.4 and 0.9 . Patients with a history of eye surgery before the diagnosis of glaucoma, or with evidence of secondary glaucoma, such as exfoliation, pigment dispersion or uveitis, were excluded. The patients with POAG who met the inclusion criteria were selected consecutively at the İstanbul University Cerrahpasa Medical Faculty Ophthalmology Department. The mean age of patients in the glaucoma group was 61.3 (6.9) years (range $48-79$ years), and $70(49 \%)$ of them were men.

Age-matched healthy volunteers presenting to our outpatient department with non-specific ocular complaints, such as

Abbreviations: GHT, glaucoma hemifield test; GST, glutathione S transferase; IOP, intraocular pressure; PCR, polymerase chain reaction; POAG, primary open-angle glaucoma; ROS, reactive oxygen species 


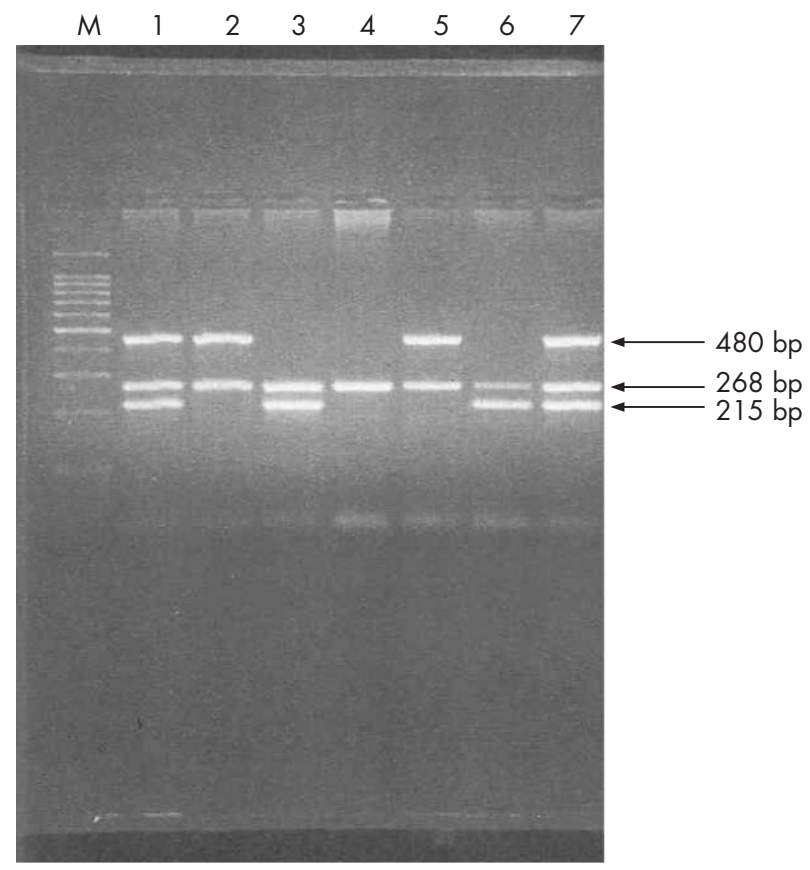

Figure 1 Polymerase chain reaction (PCR) analysis of glutathione $S$ transferase (GST) gene polymorphism. The line with 480 bp stands for GSTT1, 268 bp for $\beta$ globin and 215 bp for GSTM1. Column M represents a PCR weight marker, columns 1 and 7 GSTT1 positive/GSTM1 positive, columns 2 and 5 GSTT1 positive/GSTM1 null, columns 3 and 6 GSTT1 null/GSTM1 positive and column 4 GSTT1 null/GSTM1 null.

conjunctivitis, blepharitis, burning, itching or presbyopia were selected randomly as a control group. They had clinically healthy appearing optic discs as shown by indirect ophthalmoscopy, with a cup-to-disc ratio of $\leqslant 0.3$ and GHT within normal limits. They also lived in the same city and had no family or personal history of glaucoma. The mean IOP level of the controls was 14.3 (2.3) $\mathrm{mm} \mathrm{Hg}$ (range 8-20 mmHg). The mean age of subjects in the control group was 59.1 (5.8) years (range $51-75$ years), and 66 (55\%) of them were men.

\section{Blood samples and DNA isolation}

Venous blood samples were obtained and collected into sterile siliconised EDTA 5-ml vacutainer tubes. Immediately after collection, whole blood was stored in aliquots at $-20^{\circ} \mathrm{C}$ until use. Genomic DNA was extracted from whole blood using a NucleoSpin DNA purification kit (Macherey-Nagel GmbH, Duren, Germany) according to the manufacturer's instructions.

\section{Analysis of GSTMI and GSTT1 polymorphisms}

The GSTMI and GSTT1 genetic polymorphisms were evaluated using the multiplex polymerase chain reaction (PCR) technique as described previously. ${ }^{13}$ Primers for GSTMI were $5^{\prime}$-GAACTCCCTGAAAAGCTAAAGC-3' and 5'-GTTGGGCTCAAATATACGGTGG-3', and those for GSTT1 were 5'-TTCCTTACTGGTCCTCACATCTC- $3^{\prime}$ and $5^{\prime}$-TCACCGGATCATGGCCAGCA-3'. The $\beta$-globin locus was used as an internal control to avoid false negative readings. Primers for $\beta$-globin were $5^{\prime}$-CAACTTCATCCACGTTCACC-3' and 5'-GAAGAGCCAAGGACAGGTAC-3'.

PCR was carried out in a total volume of $25 \mu \mathrm{l}$ containing $10 \mathrm{pmol} / \mathrm{l}$ of each primer, $2.5 \mathrm{mmol} / \mathrm{l}$ of magnesium chloride, $0.2 \mathrm{mmol} / \mathrm{l}$ of each deoxynucleotide triphosphate, $1 \mathrm{U}$ of Taq polymerase and $100 \mathrm{ng}$ of genomic DNA. Amplification was performed with initial denaturation at $94^{\circ} \mathrm{C}$ for $5 \mathrm{~min}$, followed by 30 cycles at $94^{\circ} \mathrm{C}$ for $1 \mathrm{~min}, 64^{\circ} \mathrm{C}$ for $1 \mathrm{~min}$ and $72^{\circ} \mathrm{C}$ for $1 \mathrm{~min}$, and a final extension at $72^{\circ} \mathrm{C}$ for $7 \mathrm{~min}$.
The amplified products were identified by electrophoresis in a $1.5 \%$ agarose gel and stained with $0.5 \mu \mathrm{g} / \mathrm{ml}$ ethidium bromide. The product lengths were 215,480 , and 268 bp for GSTMl, GSTT1 and $\beta$-globin, respectively (fig 1 ). The absence of PCR product for GSTMI or GSTT1 in the presence of the $\beta$-globin band was indicative of a null genotype for GSTMl or GSTT1. Individuals with one or two copies of the relevant gene were classified as a "present" genotype and those with homozygous deletions as a "null" genotype.

\section{Statistical analysis}

The ages of the patient and control groups were compared using Student's t test. The $\chi^{2}$ test was applied to compare differences in sex and GSTMI and GSTTl polymorphisms between patients and controls. Significance was set at $\mathrm{p}<0.05$. Odd ratios (OR) and $95 \%$ confidence intervals (CI) were used to analyse the occurrence of frequencies of the GSTMI and GSTT1 genotypes in patients with glaucoma compared with the controls group. All analyses were performed using SPSS V.11.5 statistical analysis software.

\section{RESULTS}

Table 1 shows the demographic data of the patients. The groups were not significantly different with respect to age and sex $(\mathrm{p}>0.05)$.

Table 2 shows the genotypes for each gene. The frequency of the GSTMI positive genotype was significantly higher in patients with glaucoma $(78.5 \%)$ than in controls $(55 \%)$. The GSTMI positive genotype had an increased risk of developing POAG ( $\mathrm{p}<0.001$, OR $2.93,95 \%$ CI 1.66 to 5.20$)$.

The frequency of the GSTT1 null genotype was significantly higher in patients with glaucoma $(48.7 \%)$ than in controls (18.2\%). The GSTTI null genotype also had an increased risk of developing POAG ( $\mathrm{p}<0.001$, OR $4.25,95 \%$ CI 2.30 to 7.80$)$.

Table 3 shows the association between GST genotype profile and the development of POAG. The risk of glaucoma also increased statistically significantly in patients with a combination of GSTMl positive and GSTT1 null genotypes ( $p<0.005$, OR $3.46,95 \%$ CI 1.64 to 7.38 ).

\section{DISCUSSION}

Most genetic polymorphisms do not cause a recognisable change in the organism in which they occur. However, some either cause a disease or alter disease susceptibility. ${ }^{14}$ A large number of studies has attempted to show links between disease susceptibility and GST polymorphic variants. In addition, some studies have focused on the risk of association between the GST polymorphisms and ocular diseases including cataract, ${ }^{15-18}$ senile macular degeneration ${ }^{19}$ and glaucoma. ${ }^{3020-22}$ In this study, we determined the effects of genetic polymorphisms of GSTMI and GSTTI on the risk of POAG in a Turkish population.

\begin{tabular}{lll} 
Table 1 & Demographic data of the study patients \\
\hline & $\begin{array}{l}\text { Glaucoma group } \\
(\mathbf{n}=144)\end{array}$ & $\begin{array}{l}\text { Control group } \\
(\mathbf{n}=121)\end{array}$ \\
\hline $\begin{array}{l}\text { Number of patients } \\
\text { Sex }\end{array}$ & 144 & 121 \\
$\quad$ Male, $n(\%)$ & $70(49)$ & $66(55)$ \\
Female, $\mathrm{n}(\%)$ & $74(51)$ & $55(45)$ \\
$\begin{array}{l}\text { Age (years) } \\
\text { Mean (SD) } \\
\text { Range }\end{array}$ & $61.3(6.9)$ & $59.1(5.8)$ \\
\hline
\end{tabular}




\begin{tabular}{|c|c|c|c|}
\hline Genotype & $\begin{array}{l}\text { Patients with } \\
\text { glaucoma } \\
\text { ( } n=144) \\
n(\%)\end{array}$ & $\begin{array}{l}\text { Controls } \\
(n=121) \\
n(\%)\end{array}$ & $\begin{array}{l}\text { OR } \\
(95 \% \mathrm{Cl})\end{array}$ \\
\hline \multicolumn{4}{|l|}{ GSTMI } \\
\hline $\begin{array}{l}\text { Present } \\
\text { Null }\end{array}$ & $\begin{array}{l}113(78.5) \\
31(21.5)\end{array}$ & $\begin{array}{l}67(55) \\
54(45)\end{array}$ & $\begin{array}{l}1.00 \text { (Reference) } \\
2.93 \text { ( } 1.66 \text { to } \\
5.20)\end{array}$ \\
\hline \multicolumn{4}{|l|}{ GSTTI } \\
\hline Present & 74 (51.3) & 99 (81.8) & $\begin{array}{l}1.00 \\
\text { (Reference*) }\end{array}$ \\
\hline Null & $70(48.7)$ & 22 (18.2) & $\begin{array}{l}4.25(2.33 \text { to } \\
7.81)\end{array}$ \\
\hline
\end{tabular}

As the pathogenic role of ROS in glaucoma has been suggested by many studies, cellular defence mechanisms alleviating the toxic manifestations of oxidative insult must have an important role in protection against the development of glaucoma. As GST enzymes are one of the important families of enzymes against oxidative stress, their genetic polymorphisms may alter the critical function of the enzymes in protecting against electrophiles and the products of oxidative stress in glaucoma.

Izzotti et $a l^{3}$ reported that POAG was associated with the GSTMI null genotype in an Italian population. In addition, in a recent study, the GSTMI null genotype has been found to be associated with an increased incidence of POAG in a Turkish population. ${ }^{21}$ In contrast, another study by Jansson et $a^{22}$ reported that there was no evidence of association between GSTM1 polymorphism and glaucoma in the Swedish population.

In this study, we found that the GSTMI positive genotype was a risk factor for developing POAG. Juronen et al, ${ }^{10}$ who were the first to examine the possible association between the polymorphic GST genotypes and adult-onset POAG, also found a similar relationship between the GSTMl genotype and the incidence of POAG. They found that the frequency of GSTMI positive individuals was significantly higher in the glaucoma group compared with the control group. They suggested that the GSTMI positive phenotype might be a genetic risk factor for the development of POAG. Our results also show a correlation between the GSTMI positive genotype and the incidence of POAG.

We believe that several factors might explain the association between the GSTMI positive genotype and POAG. Although GST enzymes catalyse detoxification reactions, they also take part in reactions that result in toxic products, which may cause structural changes in the proteins present in the trabecular meshwork and aqueous humor. This can lead to aggregation or modification of the proteins in the trabecular meshwork and promote the development of POAG.$^{10}$ In addition, subjects with the GSTMI null genotype have been shown to express fewer GST mu-class enzymes than subjects with the GSTMI positive genotype. ${ }^{23}{ }^{24}$ This may selectively cause stimulation of other non-toxic end products producing biotransformation enzyme systems to detoxify the substrates that were originally detoxified by the GST enzymes.

Further evidence for involvement of GSTM in glaucoma comes from studies on autoimmunity. Yang et al showed that GST antigen was found in 52\% of cases with glaucoma and in $20 \%$ of controls $(\mathrm{p}<0.05)$. The patients had significantly higher titres of anti-GST antibody compared with controls.
Table 3 Association between glutathione $S$ transferase genotype profile and the development of primary open angle-glaucoma

\begin{tabular}{|c|c|c|c|c|}
\hline GSTMI & GSTT1 & $\begin{array}{l}\text { Patients with } \\
\text { glaucoma } \\
\text { n (\%) }\end{array}$ & $\begin{array}{l}\text { Controls } \\
\text { n (\%) }\end{array}$ & OR $(95 \% \mathrm{Cl})$ \\
\hline $\begin{array}{l}\text { Present } \\
\text { Present } \\
\text { Null } \\
\text { Null }\end{array}$ & $\begin{array}{l}\text { Present } \\
\text { Null } \\
\text { Present } \\
\text { Null }\end{array}$ & $\begin{array}{l}59(40.9 \%) \\
54(37.5 \%) \\
15(10.5 \%) \\
16(11.1 \%)\end{array}$ & $\begin{array}{l}53(43.8 \%) \\
14(11.5 \%) \\
46(38.0 \%) \\
8(6.7 \%)\end{array}$ & $\begin{array}{l}1 \text { (Reference) })^{*} \\
3.46(1.64 \text { to } 7.38) \\
0.29(0.13 \text { to } 0.61) \\
0.55(0.20 \text { to } 1.52)\end{array}$ \\
\hline \multicolumn{5}{|c|}{$\begin{array}{l}\text { GST, glutathione S transferase. } \\
\text { *Reference group; individuals with two putative low-risk genotypes (the } \\
\text { presence of GSTM1 (non-deleted) and GSTT1 (non-deleted)). }\end{array}$} \\
\hline
\end{tabular}

Furthermore, the related retinal antigen belonged to the GST $\mathrm{mu}$ class. ${ }^{25}$ Thus, it may be hypothesised that people who express GSTMl are at increased risk of developing autoantibodies against this protein, which is connected to an increased risk of developing glaucoma. Interestingly, in this study, we also found that although the frequency of the GSTMI positive genotype in the control group was similar to the other Caucasian populations of Europe, ${ }^{1022} 26$ it was significantly higher in subjects with glaucoma.

The GSTT1 null genotype was also reported in some studies to be associated with an increased tendency for some diseases including cancers and precancerous lesions. ${ }^{5} 2728$ Our study is the first to report a significant association between the GSTT1 null genotype and POAG. Previous studies on the association between the GSTTl genotype and POAG did not find a significant relationship. As discussed earlier, as well as detoxifying exogenous electrophilic xenobiotics, GST enzymes including GSTTl inactivate endogenous end products formed as secondary metabolites during oxidative stress. They are protective against many toxicants, and it may be important to reach a proper balance between the detrimental and beneficial effects of the enzyme. Altered GST activity due to genetic mutations has been shown to modulate an individual's susceptibility to environmental factor-induced diseases, including cancers. ${ }^{7} 29$

The present study suggests that the GSTMl positive genotype and GSTT1 null genotype may be genetic risk factors for development of POAG. Any combination of these two genotypes further increases the risk of POAG. It has already been suggested that the combination of the GST polymorphisms rather than individual polymorphisms makes humans more susceptible to genotoxic insults. ${ }^{26} 29$

Many factors might account for the difference in results between similar studies. Firstly, it may reflect the differences in the ethnic, genetic and environmental background of the populations studied. For instance, GSTTl deficiency is less frequent than GSTMI deficiency, but in both cases the frequency in the population varies between different ethnic groups. ${ }^{30}$ There may be differences even in the same population because of genetic and environmental factors. Studies on the Turkish population showed that the percentage of GSTMI null genotype ranged from $16 \%$ to $51.9 \%$, and that of GSTTl null genotype between $17.3 \%$ and $20 \%{ }^{26}$ This may be one of the factors responsible for the different results in the study by Ylldırım et al, ${ }^{21}$ reporting that the GSTMl null genotype was associated with an increased incidence of POAG in Turkish population. Whereas their study population lived in a small and closed city in the south of Turkey, our patients and controls were from a crowded and cosmopolitan city, which has a high number of migrants from other cities of Turkey. Thus, the subjects in our study may reflect more accurately the genetic status of the whole Turkish population. 
Secondly, the differences in the number of subjects studied in genetic researches may also lead to different outcomes. Thirdly, methodological issues should also be considered. For example, Jansson et al, ${ }^{22}$ who reported that there was no evidence of association between GSTMI and glaucoma in the Swedish population, used two methods for genotyping: multiplex PCR and pyrosequencing. In contrast, Juronen et al performed their analysis using only ELISA. ${ }^{10}$ The GST genes are located in complex genomic regions that could be affected by copy number variation and rearrangements, so different genotyping methods could give different results.

In conclusion, this study is only one in a series of casecontrol studies on the possible association between glaucoma and GST. Some found evidence of GST positive genotypes being predisposed to glaucoma, and others that GST positive genotypes are protected from glaucoma. These results imply that further studies of the precise mechanisms by which genetic polymorphisms of metabolising enzymes influence the nature and history of glaucoma development are merited.

\section{Authors' affiliations}

Mustafa Ünal, Department of Ophthalmology, Akdeniz University Medical Faculty, Antalya, Turkey

Mehmet Güven, Ahmet Özaydın, Bahadır Batar, Department of Medical Biology, Cerrahpasa Faculty of Medicine, University of Istanbul, Istanbul, Turkey

Kazım Devranoğlu, Nevbahar Tamçelik, Ebru Eroğlu Görgün, Didar Uçar, Ahmet Sarıci, Department of Ophthalmology, Cerrahpasa Faculty of Medicine, University of Istanbul, Istanbul, Turkey

Competing interests: None declared.

\section{REFERENCES}

1 Izzotti A, Bagnis A, Sacca SC. The role of oxidative stress in glaucoma. Mutat Res 2006;612:105-14.

2 Izzotti A, Di Marco B, De Flora S, et al. Open angle glaucoma: epidemiology, pathogenesis and prevention. Recent Prog Med 2006;97:37-45.

3 Izzotti A, Sacca SC, Cartiglia C, et al. Oxidative deoxyribonucleic acid damage in the eyes of glaucoma patients. Am J Med 2003;114:638-46.

4 Moreno MC, Campanelli J, Sande P, et al. Retinal oxidative stress induced by high intraocular pressure. Free Radic Biol Med 2004;37:803-12.

5 Habdous M, Siest G, Herbeth B, et al. Glutathione S-transferases genetic polymorphisms and human diseases: overview of epidemiological studies. Ann Biol Clin (Paris) 2004;62:15-24.

6 Strange RC, Spiteri MA, Ramachandran S, et al. Glutathione-S-transferase family of enzymes. Mutat Res 2001;482:21-6.

7 Zhong SL, Zhou SF, Chen X, et al. Relationship between genotype and enzyme activity of glutathione S-transferases $\mathrm{MI}$ and $\mathrm{Pl}$ in Chinese. Eur J Pharm Sci 2006;28:77-85.

8 Hayes JD, Flanagan JU, Jowsey IR. Glutathione transferases. Annu Rev Pharmacol Toxicol 2005;45:51-88.
9 Board PG, Baker RT, Chelvanayagam G, et al. Zeta, a novel class of glutathione transferases in a range of species from plants to humans. Biochem $J$ 1997;328:929-35.

10 Juronen E, Tasa G, Veromann S, et al. Polymorphic glutathione S-transferase M1 is a risk factor of primary open-angle glaucoma among Estonians. Exp Eye Res 2000;71:447-52.

11 Xu S, Wang Y, Roe B, et al. Characterization of the human class Mu glutathione S-transferase gene cluster and the GSTM1 deletion. J Biol Chem 1998;273:3517-27.

12 Pemble S, Schroeder KR, Spencer SR, et al. Human glutathione S-transferase theta (GSTT1): cDNA cloning and the characterization of a genetic polymorphism. Biochem J 1994;300:271-6.

13 Arand M, Muhlbauer R, Hengstler J, et al. A multiplex polymerase chain reaction protocol for the simultaneous analysis of the glutathione S-transferase GSTM1 and GSTI1 polymorphisms. Anal Biochem 1996;236:184-6.

14 Cohen CS, Allingham RR. The dawn of genetic testing for glaucoma. Curr Opin Ophthalmol 2004;15:75-9.

15 Saadat M, Farvardin-Jahromi M. Occupational sunlight exposure, polymorphism of glutathione S-transferase M1, and senile cataract risk. Occup Environ Med 2006;63:503-4.

16 Alberti G, Oguni M, Podgor M, et al. Glutathione S-transferase M1 genotype and age-related cataracts. Lack of association in an Italian population. Invest Ophthalmol Vis Sci 1996;37:1 167-73.

17 Hao Y, He S, Gu Z, et al. Relationship between GSTMI genotype and susceptibility to senile cataract. Zhonghua Yan Ke Za Zhi 1999;35:104-6.

18 Sekine Y, Hommura S, Harada S. Frequency of glutathione-S-transferase 1 gene deletion and its possible correlation with cataract formation. Exp Eye Res 1995;60:159-63

$19 \mathrm{Oz} \mathrm{O}$, Aras Ates N, Tamer L, et al. Glutathione S-transferase M1, Tl, and P1 gene polymorphism in exudative age-related macular degeneration: a preliminary report. Eur J Ophthalmol 2006;16:105-10.

20 Yilmaz A, Tamer L, Ates NA, et al. Is GST gene polymorphism a risk factor in developing exfoliation syndrome? Curr Eye Res 2005;30:575-81.

21 Yildirim O, Ates NA, Tamer L, et al. May glutathione S-transferase M1 positive genotype afford protection against primary open-angle glaucoma? Graefe's Arch Clin Exp Ophthalmol 2005;243:327-33

22 Jansson M, Rada A, Tomic L, et al. Analysis of the glutathione S-transferase M1 gene using pyrosequencing and multiplex $P C R-$ no evidence of association to glaucoma. Exp Eye Res 2003;77:239-43

23 Anttila S, Luostarinen L, Hirvonen A, et al. Pulmonary expression of glutathione S-transferase $M 3$ in lung cancer patients: association with GSTM1 polymorphism, smoking, and asbestos exposure. Cancer Res 1995;55:3305-9.

24 Nakajima T, Elovaara E, Anttila S, et al. Expression and polymorphism of glutathione S-transferase in human lungs: risk factors in smoking-related lung cancer. Carcinogenesis 1995;16:707-11.

25 Yang J, Tezel G, Patil RV, et al. Serum autoantibody against glutathione Stransferase in patients with glaucoma. Invest Ophthalmol Vis Sci $2001 ; 42: 1273-6$

26 Ada AO, Suzen SH, Iscan M. Polymorphisms of cytochrome P450 1A1, glutathione S-transferases $\mathrm{Ml}$ and $\mathrm{T} 1$ in a Turkish population. Toxicol Lett 2004;151:311-15.

27 Barroso Duarte EC, Da Silva MS, Gomez MV, et al. GSTT1 polymorphism and oral leukoplakia. Anticancer Res 2006;26:427-30.

28 Boccia S, La Torre G, Gianfagna F, et al. Glutathione S-transferase T1 status and gastric cancer risk: a meta-analysis of the literature. Mutagenesis 2006;21:115-23.

29 Tars K, Larsson AK, Shokeer A, et al. Structural basis of the suppressed catalytic activity of wild-type human glutathione transferase T1-1 compared to its W234R mutant. J Mol Biol 2006:355:96-105.

30 Johansson AS, Mannervik B. Interindividual variability of glutathione transferase expression. In: Pacifici GM, Pelkonen O, eds. Interindividual variability of glutathione transferase expression. London: Taylor \& Francis, 2001:460-519. 